\title{
La Paremiologia catalana comparada de Sebastià Farnés i el seu estudi des d'una perspectiva de gènere
}

\author{
Carme Oriol Carazo \& Magí Sunyer Molné \\ Universitat Rovira i Virgili \\ carme.oriol@urv.cat / magi.sunyer@urv.cat
}

\begin{abstract}
RESUM
La Paremiologia catalana comparada, de Sebastià Farnés, es va publicar en vuit volums entre els anys 1992 i I999 a partir dels materials manuscrits que el folklorista va elaborar al llarg de la seva vida i que van restar inèdits després de la seva mort, l'any I934. En aquest treball s'expliquen les circumstàncies que van envoltar l'edició, els criteris que es van seguir per a l'ordenació i la presentació de les parèmies i les possibilitats d'estudi que ofereix l'obra. A continuació, des de la perspectiva dels estudis de gènere, s'estudia com es projecta la imatge de la dona (com és, com ha de ser o com s'ha de comportar) en un total de 343 parèmies contingudes a l'entrada «dona» d'aquesta magna obra. Els resultats del treball mostren la importància i la vigència del treball realitzat per Farnés per a la realització d'estudis descriptius i analítics.
\end{abstract}

PARAules CLAU

estudis de gènere; folklore; literatura; parèmia; Sebastià Farnés

\section{ABSTRACT}

The volume Paremiologia catalana comparada, by Sebastià Farnés, was published in eight volumes between the years 1992 and I999. It was based on the manuscript materials that the folklorist created throughout his life and which remained unpublished until after his death in 1934. In this article we explain the circumstances surrounding their publication, the criteria by which the proverbs were organized and presented and the possibilities of study offered by the work. We then adopt a gender studies perspective in order to study how women are depicted (how women are, how they should be or how they should behave) in the 343 proverbs listed under the subheading "Woman" in this great work. The results of our research show the importance and relevance of Farnés' work to current descriptive and analytical studies.

KEYWORDS

gender studies; folklore; literature; proverb; Sebastià Farnés

REBUT: I/O3/2OI8 | ACCEPTAT: 20/O3/20I8 


\section{Introducció}

L'aportació de Sebastià Farnés a l'estudi de la paremiologia és d'una vàlua indiscutible. ${ }^{I}$ L'autor va dedicar tota la seva vida a l'arreplega i a l'estudi de les parèmies i, fruit d'aquesta dedicació, va realitzar diversos articles i monografies. A la revista La Renaixensa va publicar tres articles: «Un refran popular» (I882), «Refrans catalans» (I883) i, també amb el mateix títol, «Refrans catalans» (I884a); i a la Ilustració Catalana, l'article «Refrans catalans. Qui no't conegui que't compri» $(\mathrm{I} 884 b)$. En tots aquests treballs, les versions catalanes es posen en relació amb versions equivalents en altres llengües, la qual cosa ja denota un interès de l'autor per la paremiologia comparada.

De I9I3 és el llibre Assaig de paremiologia catalana comparada, que Farnés va concebre com el primer volum de la que havia de ser la Paremiologia catalana comparada. En el llibre publicat el I9I3 hi ha 259 entrades paremiològiques diferents per a la seqüència «A-Amic», amb indicació de variants, comentaris de l'autor i referències bibliogràfiques.

L’any I9I8, Farnés va publicar a la revista Catalana l'article «Folklore: Paremies-endevinetes. Les tres gallines» i, finalment, a Arxiu de Tradicions Populars va publicar cinc articles: «Demofilologia. Literatura oral. Sant Joan, bon sant» (I928), «Demofilologia. Literatura oral. Dues cultures» [I929-I933a], «Demofilologia. Literatura oral. Una endevineta proverbial» [I929-I933b], «Demofilologia. Literatura oral. Motius del rei En Pere d'Aragó» (I933) i «Demofilologia. Literatura oral. Veïns perillosos» (I935). En tots aquests articles, el treball de Farnés es va dirigir, fonamentalment, a interpretar el significat de les parèmies que va estudiar. ${ }^{2}$

Però la culminació del seu treball va ser la Paremiologia catalana comparada que va restar inèdita després de la mort del folklorista, l'any I934, i que es va publicar finalment entre els anys I992 i I999 en una edició en vuit volums a cura de Jaume Vidal Alcover, Magí Sunyer i Josep Lluís Savall, amb la col-laboració de Josep M. Pujol.

L'article que ara es publica pren com a objecte d'estudi aquesta darrera obra. En primer lloc, s'analitzen les circumstàncies que van envoltar l'edició, el seu valor en tant que obra paremiològica singular (que depassa el valor estricte d'un diccionari de parèmies), i el pas de les fitxes manuscrites a la lletra impresa. ${ }^{3}$ En segon lloc, s'exploren les possibilitats que l'obra ofereix per a la recerca i, així, des de la perspectiva dels estudis de gènere, s'analitza com es projecta la imatge de la dona (com és, com ha de ser o com s'ha de comportar) en 343 parèmies que es troben a l'entrada «dona». ${ }^{4}$

\footnotetext{
I Aquest article forma part de la investigació del grup Identitat Nacional i de Gènere a la Literatura Catalana, de la Universitat Rovira i Virgili, i del Grup de Recerca Identitats en la Literatura Catalana (GRILC), consolidat per la Generalitat de Catalunya (20I7 SGR 599) i s'ha realitzat en el marc d'un projecte d'R+D sobre literatura popular catalana que ha rebut finançament del Ministerio de Economía y Competitividad (FFI2OI5-64I28-P [MINECO/ FEDER]).

2 Per a més detalls sobre aquestes obres de Farnés, vegeu Oriol (20II).

3 El desenvolupament d'aquesta primera part del treball correspon a Magí Sunyer.

4 L'autoria d'aquesta segona part correspon a Carme Oriol.
} 


\section{Circumstàncies de l'edició}

Entre els anys I983 i I999 es va desenvolupar el procés d'edició de la Paremiologia catalana comparada, de Sebastià Farnés. El període hauria pogut ser força més breu, però hi van jugar en contra circumstàncies logístiques i personals d'índole diversa. Algunes van ser tècniques, i van alentir extraordinàriament la preparació d'una enciclopèdia de més de vuit mil pàgines. L'inici de la gran transformació tecnològica que va conduir de la màquina d'escriure al processador de textos i a Internet es va produir, per als usuaris finals, tot just en aquells primers anys vuitanta. La informació de la Paremiologia es va començar a introduir, com a gran novetat de progrés, amb una màquina d'escriure elèctrica que permetia rectificar text - les tres darreres línies! - sense haver de tornar a picar-lo. La introducció dels primers processadors de textos - primer un Amstrad, que llavors semblava una meravella tecnològica gairebé miraculosa; després un processador molt més avançat, amb prestacions superiors; després, encara, un portàtil—, que proporcionaven innegables avantatges va obligar a rectificacions i recomençaments de feina. La del primer any es va haver de llençar sencera per tornar a començar. No va ser l'únic obstacle que es va interposar en el pas de les fitxes als volums impresos.

L'edició de la Paremiologia era un projecte vital, personal, de Maria Aurèlia Capmany. El record del seu avi Sebastià Farnés es va mantenir amb una intensitat superior en la neta; l'evocació de la casa de Canet, amb l'avi i les ties, era freqüent en la conversa i ocupa un espai destacat en els seus textos memorialístics. Se'n sentia hereva i no tan sols biològicament, en la seva adscripció al catalanisme pesava l'herència dels pares, de les ties i, sobretot, de l'avi Farnés. La Paremiologia era el material més sòlid d'aquest llegat. A partir d'algun moment de la seva vida, les més de cent cinquanta carpetes amb unes dues-centes fitxes cadascuna van ocupar una prestatgeria que es traslladava a cada una de les residències de l'escriptora, amb estada final —en vida seva - al carrer de les Coques de Tarragona. Allí, en un despatx a tocar de la catedral, Josep Lluís Savall i qui signa aquesta primera part de l'article hi vam treballar fins a la mort de Jaume Vidal Alcover i Maria Aurèlia Capmany, quan la casa es va desmuntar i, per disposició testamentària dels dos escriptors - amb renúncia prèvia, en el cas de Maria Aurèlia Capmany, de les seves nebodes Mercè i Anna-, llibres i documents, juntament amb els del pis de la plaça Reial de Barcelona i alguns del carrer de Brondo de Mallorca, van constituir el Fons Vidal Capmany de la Facultat de Lletres de la Universitat Rovira i Virgili. Sebastià Farnés va enriquir el diccionari paremiològic durant tota la vida, però només en va publicar un volumet que hauria hagut d'iniciar una llarga sèrie però que va esdevenir únic: l'Assaig de paremiologia catalana comparada (Farnés I9I3). L'ingrés de Maria Aurèlia Capmany en l'activitat política professional li va facilitar els contactes en les institucions -Ajuntament de Barcelona, Diputació de Barcelona, Generalitat de Catalunya- que van permetre subvenir les despeses d'edició i de publicació de l'obra. Un somni de moltes dècades que va veure com es començava a concretar però que no va poder veure acomplert: el primer volum es va publicar l'any i992, un després que l'escriptora morís.

L'equip d'edició va quedar constituït per Jaume Vidal Alcover, Josep Maria Pujol, Magí Sunyer i Josep Lluís Savall. Els dos primers havien de desenvolupar funcions de direcció que, fixats els criteris inicials, van quedar reduïdes al disseny de la maqueta per part de Josep Maria Pujol. Mort Jaume Vidal l'any I99i —es 
va mantenir el seu nom com a redactor-, Josep Maria Pujol, a petició seva, ja només hi va constar com a col-laborador. L'esmentat disseny no es va limitar a l'aspecte que havia de tenir la pàgina de llibre, sinó que incorporava una sèrie de codis — que s'escrivien dintre de parèntesis d'angle- que permetien la transformació automàtica en l'aspecte final de cada cos i tipus de lletra, incloses majúscules, versaletes i cursives. Aquesta particularitat, que va facilitar molt la feina de composició, va dificultar i alentir molt la preparació del material per la necessitat de picar contínuament codis, en una feina que no es visualitzava. Ara, quan es té el resultat a la vista, no es pot arribar a sospitar l'esforç que va suposar en el picatge de les fitxes. No cal detallar l'itinerari que va seguir la recerca d'una editorial adequada per a un projecte d'aquestes dimensions. Se'n va fer càrrec Columna Edicions, que, a partir de l'aparició del primer volum, va publicar els vuit volums a un ritme puntual d'un per any fins al I999 i la va proveir d'un elegant disseny de la coberta enquadernada en pell.

\section{Més que un diccionari de parèmies}

Sebastià Farnés i Badó (Sant Feliu de Codines, I854 - Barcelona, I934) fou advocat i periodista, ${ }^{5}$ teòric del catalanisme, ${ }^{6}$ professor de taquigrafia ${ }^{7}$ i folklorista. ${ }^{8}$ Quan es va retirar de l'activitat política, es va concentrar en l'estudi del folklore, com a resultat del qual ja havia publicat narracions populars catalanes i, de manera preferent, en el seu gran diccionari de parèmies.

La Paremiologia és l'obra d'una vida. El folklorista hi va començar a treballar als setze anys i, ni que, tal com s'ha apuntat, altres activitats li reclamessin temps, esforços i entusiasmes, no va deixar de dedicar-s'hi. Ell mateix ho va expressar, amb relació al seu sentiment nacional, en un extens pròleg que va deixar preparat per a la definitiva publicació de la seva obra magna: «Ella és el conjunt de mes amors, gairebé diria que és la meva història íntima: mon viatge no a la recerca de l'ideal, sinó a la reivindicació del patrimoni dels catalans, del meu patrimoni espiritual» (Farnés I992-I999, I: I5). El sentit renaixencista de l'empresa s'acaba d'aclarir en la contundència amb què justifica les raons que el van empènyer a ocupar-se'n: «hem treballat per refer nostre patrimoni espiritual, desconegut, menyspreuat i arraconat pertot arreu: es tracta, doncs, amb nosaltres, de refer, de reconstituir el patrimoni nacional, busquem una cosa positiva, que existeix, que viu entre nosaltres» (Farnés I992-I999, I: I5). El mètode comparatista també va associat a aquest sentiment catalanista que es fonamenta en la llengua i les parèmies i s'insereix en l'objectiu d'assolir la plena llibertat nacional, en l'horitzó de la independència, quan marca la diferència entre l'estudi del folklore en països com França, Itàlia,

5 Va col-laborar en publicacions com Diari Català, La Renaixença, L'Arc de Sant Martí i La Veu de Catalunya, entre d'altres.

6 Fou un activista del Centre Català de Valentí Almirall i de la Unió Catalanista. Per a aquesta faceta, s'ha de remetre als estudis de Jordi Llorens i Vila, que l'any I980 va llegir una tesi a la Universitat de Barcelona titulada «L'aportació de Sebastià Farnés al Catalanisme» i ha publicat articles i pròlegs sobre el tema.

7 Va fundar l'Institut Taquigràfic de Barcelona, va col-laborar amb Pere Garriga i Marill en la fundació de l'Instituto Taquigráfico Español i va publicar llibres sobre aquesta disciplina. 8 Va ser col-laborador de l'Arxiu d'Etnografia i Folklore de Catalunya, dirigit per Tomàs Carreras i Artau. 
Espanya o Portugal i el nostre: «nosaltres els catalans recollim monedes que el tirà barbre ha declarat fora de circulació, i les recollim no pas per estotjar-les, sinó per fer-les circular, perquè ja sabem ben bé del cert que aquestes monedes constitueixen el preu del deslliurament de l'esclavatge que patim; perquè en nostre pelegrinatge a Roma, que ens han imposat per penitència, hem de proveir-nos del propi idioma com a condició indispensable de rescat» (Farnés I992-I999, I: 23). Encara més, Sebastià Farnés concep la paremiologia com una constatació de la cohesió dels Països Catalans: «Les parèmies ens assenyalaran amb tota precisió la unitat de l'esperit de la nació catalana dins la gran varietat de sos dialectes; perquè Catalunya té en això tots els caràcters d'una família: unitat de vincle, de parentia i varietat entre els germans, que són de distinta alçària, de color de cabells diferents, de complexions, d'aficions, de genis diversos» (Farnés I992-I999, I: 29).

A partir d'aquestes afirmacions, podem comprendre que l'ambició de la Paremiologia catalana comparada de Sebastià Farnés no era proporcionar un diccionari de refranys, sinó bastir una obra de referència, de caràcter nacional, en què el comparatisme contextualitzés i reforcés la consideració del ric patrimoni paremiològic català. L'hem de situar en el context de les grans obres amb què qualsevol cultura rica compta, de la mena, entre les catalanes, dels Diccionari català-valencià-balear, d'Antoni Maria Alcover i Francesc de Borja Moll, o el Diccionari etimològic i complementari de la llengua catalana, de Joan Coromines.

\section{De les fitxes a la lletra impresa}

En aquest mateix pròleg, Sebastià Farnés proporciona la informació sobre el procés d'incorporació de parèmies i sobre el mètode seguit i les fonts que va utilitzar. Des de la primera enquesta a sa mare - la majoria de les parèmies que consten com a recollides a Sant Feliu de Codines- fins a diccionaris i reculls de refranys o obres literàries com el Tirant lo Blanc o Don Quijote de la Mancha, unes quatre mil referències que figuren en una rica bibliografia que va ser difícil d'establir abans de l'era d'Internet i que - malgrat els esforços que s'hi van esmerçar — va resultar impossible de completar.

De cara a la posteritat, un dels encerts més evidents de Sebastià Farnés fou escollir el mot «parèmia» en comptes dels més usuals «adagi», «refrany», «proverbi», «referta», «dita» o «aforisme». És probable que la tria faci minvar la popularitat del títol, però, per altra part, li proporciona una pàtina científica que, passat un segle des de la publicació del primer i únic lliurament de l'obra en vida de l'autor, n'afavoreix la valoració, més encara quan el nom de la disciplina que l'estudia s'anomena paremiologia. ${ }^{9}$ En el pròleg esmentat, Sebastià Farnés va justificar la seva opció entre les altres possibilitats: «He triat de tota la diversitat de noms, el de parèmia que els hi dóna el grec, perquè ell expressa el caràcter més típic de les dites populars, "d'apuntar a un fitó vistent i acceptar-ne un altre de ben diferent". Aquest, en realitat, és el joc més plaent al poble» (Farnés I992-I999, I: 23).

Sebastià Farnés devia ser un treballador pulcre, ordenat. Les fitxes de la Paremiologia ens han arribat prou polides, però és inevitable que un material que va anar creixent durant tota la vida de l'autor necessités una preparació per convertir-lo

9 Els estudis catalans sobre la matèria s'han renovat gràcies a la dedicació de Maria Conca i Josep Guia. Vegeu el manual Conca (I990) i els nombrosos treballs que sobre la matèria han publicat aquests dos estudiosos, entre els quals, Conca i Guia (20I4). 
en llibre. Farnés anava acumulant informació i, a l'hora d'editar-la, calia ordenar-la, tal com ell mateix ho hauria fet si n'hagués tingut ocasió. L'únic volum que en va poder publicar és una bona mostra de com ell concebia el resultat final. La Paremiologia, tal com explicita el títol, és comparada, i, a més de les formes catalanes de base, és habitual que incorpori correspondències en castellà i en llatí, amb menys freqüència en occità i en gallec, de vegades en francès, en italià i en alguna de les altres llengües d'Itàlia — sicilià, venecià- i, de manera força menys habitual, en algun altre idioma romànic o en anglès o alemany. Quan s'incorporen parèmies de llengües que no són les esmentades, s'acostuma a fer en traducció catalana. El paremiòleg establia la forma principal de la parèmia, que encapçalava l'entrada, i, a continuació, afegia tot el material relacionat que anava trobant. Numerava les variants catalanes amb xifres romanes, les castellanes amb aràbigues i les llatines amb lletres majúscules; si n'hi havia en altres llengües, acostumaven a ser menys nombroses i no anaven numerades. Les fitxes reprodueixen fragments literaris de les formes numerades de la parèmia i d'altres que en proporcionen variants més allunyades o transformades per l'escriptor i que no es referencien en relació directa amb cap de les variants. En moltes fitxes, es remet a altres entrades de la Paremiologia amb el mateix o similar significat. Es proporcionen les explicacions dels significats de les parèmies que consten en cada llibre citat, habitualment presidides per la més precisa, a criteri de Farnés. Una abundant col-lecció de comentaris, molt sovint de gran interès i de vegades divertits, permeten, espigolant per tota l'obra, construir un retrat intel-lectual del folklorista, amb fílies i fòbies cap a determinats personatges expressades amb vehemència. Joan Amades és dels que menys ben parat hi queda. L'extensió de cada fitxa varia molt, des de l'anotació única en un parell o tres de línies fins a desenes de cartolines escrites a l'anvers i al revers en què no és estrany que hi hagi paperets enganxats, esmenes i afegits. Malgrat aquestes peculiaritats, ja s'ha fet constar que l'aspecte formal de les fitxes, més enllà del que es podria esperar com a resultat d'una vida sencera d'afegitons i de revisions, és prou endreçat.

Calia ordenar aquest material, proporcionar-li una uniformitat pròpia de les obres enciclopèdiques. Vam tenir la fortuna de comptar, per al disseny de fitxa i de pàgina, amb l'expertesa i la creativitat tipogràfica de Josep Maria Pujol. En l'obra editada, en pàgines a doble columna, les fitxes es localitzen a primer cop d'ull gràcies a la numeració correlativa dintre de cada lletra, destacada per l'ús exclusiu en els volums de la negreta. L'harmonia interna de cada entrada és resultat de l'esmentada saviesa tipogràfica. La parèmia que encapçala, exactament igual que — si n'hi ha d'altres - la que figura en primer lloc en la sèrie, es presenta actualitzada ortogràficament; altres estan reproduïdes en l'ortografia — prenormativa- de l'original, de la mateixa manera que les citacions literàries i les parèmies en altres llengües. Només, advertits per Josep Maria Escolà, filòleg llatinista, d'errors importants en les frases llatines anotades per Farnés — que possiblement provenien dels originals-, gràcies a la seva molt generosa col·laboració, a partir d'un punt es van esmenar. Al final de les sèries de referències de cada llengua, hi figura la bibliografia, per a la qual, inevitablement, es va haver d'utilitzar un doble sistema de citació: per als repertoris de refranys, diccionaris i, en general, obres científiques, es va preferir, sempre que va ser possible, fer servir el sistema data-autor per identificar el llibre o la publicació periòdica; per a les obres literàries i per a aquelles de les quals desconeixíem l'edició emprada per Farnés, la fórmula autor-títol va re- 
sultar inevitable. L'apartat de citacions sovint incorpora el passatge complet que Farnés copia per extreure'n la parèmia. Acabades les sèries de parèmies diferenciades per llengües, arriba l'espai, identificat per la paraula VeGEU, en versaletes, destinat a localitzar altres testimonis de la Paremiologia d'idèntic significat. Les explicacions del significat de la parèmia — tant les de Farnés com les d'altres estudiosos citats-, els passatges literaris que en proporcionen formes transformades i tota mena de comentaris del paremiòleg componen l'últim apartat de la fitxa, que pot arribar a adquirir una llargada considerable.

Poques cultures disposen d'una obra enciclopèdica d'aquestes dimensions. El projecte vital que per a Sebastià Farnés suposava i l'època en què es va realitzar expliquen que una obra d'aquestes dimensions sigui obra d'un home i no d'un equip, tal com seria habitual en el món científic contemporani. L'obra editada i els materials de preparació manuscrits obren moltes possibilitats als estudiosos que en vulguin extreure conclusions des de les més diverses perspectives científiques. El terreny està aplanat, només cal conrear-lo.

\section{La perspectiva de gènere en l'estudi de les parèmies}

L'estudi de les parèmies des d'una perspectiva de gènere ha estat abordat per diversos autors. En l'àmbit català, l'any I 936 el folklorista Joan Amades va publicar el llibre Refranyer de les dones en la Biblioteca de Tradicions Populars. ${ }^{\text {Io }}$ En el llibre, el folklorista fa referència a l'abundor de parèmies referides a les dones i constata que la imatge respectuosa que transmeten va lligada únicament als rols de la dona com a mare i com a mestressa de casa: «L'abundantíssim refranyer referent a la dona és posseïdor d'una agudesa i d'una agror veritablement sorprenents. En termes generals hom pot dir que el refrany només respecta la dona sota dos aspectes: la mare i la mestressa de la llar. Els documents que la consideren sota aquests aspectes són d'una selecta ponderació que contrasta notablement amb la resta» (Amades I936: 7-8).

En dates més recents, Anna M. Fernández Poncela va dedicar dos llibres a l'estudi dels estereotips masculins i femenins en les parèmies catalanes: Estereotipos y roles de género en el refranero popular (2002) i Sexe i refranyer (2004). ${ }^{\text {II }}$ Fruit de la seva recerca, l'autora observa que el refranyer conté «missatges sobre imatges i conductes apropiades i inapropiades» referides als homes i a les dones, però és «més ampli, ric, dur i groller en relació a les actituds i la conducta femenina» que no pas a la masculina (Fernández Poncela 2004: 22). Els estudis realitzats per Fernández Poncela han tingut en compte un nombre important de reculls paremiològics de diverses èpoques, entre els quals no inclou, però, la Paremiologia catalana comparada (I992-I999), de Sebastià Farnés.

Amb l'objectiu de complementar les aportacions esmentades sobre el tema, es pretén reflexionar, a continuació, sobre la imatge de la dona que transmet un total de 343 parèmies catalanes recollides a l'esmentada obra de Farnés, atesa la seva importància qualitativa i quantitativa.

Io L'any 2004, el llibre va ser reeditat per l'editorial El Mèdol.

in Anna M. Fernández Poncela ha publicat també nombrosos articles centrats en l'estudi de les parèmies des d'una perspectiva gènere. 


\section{La imatge de la dona a la Paremiologia catalana comparada}

Les parèmies referides a la dona es poden trobar en diverses entrades de la Paremiologia ${ }^{12}$ com, per exemple, «dona» (Dona jove i home vell, pobre d'ell), ${ }^{13}$ "mare» (Qui té mare, menja coca, qui no en té no en tasta gota), ${ }^{14}$ "madrastra» (De la madrastra, ni pa ni pasta), ${ }^{15}$ «filla» (A la filla, pa i cadira, i a la nora, pa i fora), ${ }^{16}$ «noia» (La noia honrada sempre és estimada), ${ }^{17}$ "donzella» (La donzella recatada serà molt bona casada), ${ }^{18}$ «muller» (El que no es puga saber, no ho digues a ta muller), ${ }^{19}$ «sogra» (Bona és la sogra si no mou guerra, però millor si la cobreix la terra), ${ }^{20}$ "viuda» (La viuda rica, amb un ull plora i amb l'altre repica), ${ }^{2 \mathrm{I}}$ en funció de quin sigui el rol femení que reflecteixi la parèmia.

De tot l'extens corpus que proporcionen aquestes entrades, tot seguit, s'analitzen, únicament, les parèmies que s'inclouen en l'entrada «dona». ${ }^{22}$ Són un total de 343 parèmies que es troben al volum 3 de l'obra i que van de D I545 ( $A$ bona dona, no hi basta preu) fins a D I888 (Ni doneta ni muleta). ${ }^{23}$

Aquestes parèmies transmeten la imatge de «com és» la dona i també de «com ha de ser o com s'ha de comportar». En general, les parèmies reflecteixen la mentalitat d'una societat de tipus agrari i contenen referents propis de la religió catòlica. Aquests trets es veuen de forma molt clara en el cas de les parèmies que estableixen una comparació entre la dona i determinats animals molt presents en el món de pagès, com ara el ruc, o en les que comparen les maneres de fer de la dona amb les del dimoni.

\subsection{Com és la dona}

La imatge de com és la dona es manifesta a través d'unes qualitats positives, unes altres de negatives i encara unes altres que es poden considerar ambivalents.

\footnotetext{
I2 També es poden trobar parèmies amb el lema «dona» en altres entrades de la Paremiologia, ja que Farnés va ordenar les parèmies d'acord amb el seu primer mot significatiu segons l'ordre jeràrquic de nom, verb i complement. En el present estudi aquestes parèmies no han estat analitzades.
}

I3 Farnés (I992-I999, vol. 3: 84I, D I626).

I4 Farnés (I992-I999, vol. 5: 849, M ioi8).

I5 Farnés (I992-I999, vol. 5: 630, M I30).

I6 Farnés (I992-I999, vol. 4: 479, F IOO5).

I7 Farnés (I992-I999, vol. 6: 455, N 4I4).

I8 Farnés (I992-I999, vol. 6: 455, N 4I3).

I9 Farnés (I992-I999, vol. 6: 323, M 2635).

20 Farnés (I992-I999, vol. 8: I22, S II34).

2I Farnés (I992-I999, vol. 8: 84I, V IO24).

22 En estudis posteriors, caldria ampliar la recerca a les parèmies que continguin el lema «dona» (singular, plural o derivat) en altres entrades de la Paremiologia, la qual cosa permetria extreure conclusions més definitives sobre el tema.

23 Farnés (I992-I999, vol. 3: 82I-90I). 


\subsubsection{Les qualitats positives}

Les qualitats positives es concreten en una de general: la dona és un bé molt preuat. Ho reflecteixen així les parèmies: Més val dona que hisenda (D I799); A on hi falta la dona, hi falta tot (D I57I). En la societat agrària tradicional, la dona era una peça fonamental en l'estructura familiar. Per això, es valorava molt que tingués qualitats positives: A bona dona, no hi basta preu (D I545); La dona bona és un tresor (D I699); La dona bona i lleial és un tresor perpetual (D I7OI).

Pel que fa a l'aparença física, les parèmies valoren especialment la dona d'estatura petita: Dona petita, de tot té una mica (D I642); La dona naneta sempre apar joveneta (D I738); Les dones petites tenen les amors grans (D I786).

\subsubsection{Les qualitats negatives}

Les qualitats negatives són molt més abundants que les positives i poden concretar-se en les següents:

I. La dona és dolenta: Dones, frares i pardals són els més dolents animals (D I670); Dones! Poques de bones (D I683); La dona i el dimoni sempre se'n pensen (D I764); Trauràs de les dones poques coses bones (D I873); Dona és cap de pecat (D I606).

2. La dona és desagraïda: Dona i ruc, als qui els manté donen coces (D I622).

3. La dona és inestable (canvia de parer): La dona és tan mudable com el vent, de ses paraules no faces fonament (D I72I).

4. La dona és conflictiva (busca-raons): Allà on hi ha dones, hi ha raons (D I565); A on governen dones perilla no haver-hi pau (Di570); Dones, gossos i criatures, raons segures (D I673).

5. La dona no és de fiar: Quan és jove, la dona, és pedra rodona; quan és vella, és pedra girella $i$, així, mai te fies d'ella (D I82I).

A aquestes característiques referides al caràcter de les dones, se n'afegeixen unes altres que defineixen els atributs de la dona en relació amb els de l'home:

6. La dona és un ésser feble (en relació amb l'home): A les dones, tot els és permès (D I562).

7. La dona és inferior a l'home: La dona és la meitat de l'home (D I7I8); La dona és estat feta per a l'home i no l'home per a la dona (D I7I9).

8. La dona és incompetent en la realització de les feines que fan els homes: Cavat de dones i llaurat de rucs, collita de pets (D I576).

Un altre grup de parèmies fa referència a la imatge física de la dona un cop casada. Aquestes parèmies se sustenten en una idea molt present en generacions anteriors a les nostres en què a la dona se la preparava per al matrimoni (l'objectiu era que es casés). Per això, la dona, de soltera, havia de mostrar tenir unes qualitats que, un cop casada, ja podia abandonar. En aquest context, els canvis físics de la dona com a conseqüència dels embarassos, dels parts i, més endavant, de la menopausa, són tractats en aquestes parèmies de forma negativa i culpabilitzant la dona. Finalment, entre les parèmies que fan referència a la relació de la dona amb l'home un cop casada, n'hi ha que es refereixen al fet que una dona bonica no convé al marit perquè és poc treballadora o bé perquè la seva bellesa pot atreure l'atenció d'altres homes.

9. La dona, quan es casa, és descurada amb la seva persona: Dona casada, dona deixada (D I594); Dóna'm dona prima i neta, que bruta i grossa ja se’n torna (D I630). 
IO. La dona bonica és poc treballadora: La dona bonica, Blai, no et farà tornar ric mai (D I702); La dona bonica no fa tornar ric (D I703).

II. La dona bonica és un perill per al marit: Qui té la dona bonica i terra prop de riera, mai li falta quimera (D I84I).

\subsubsection{Les qualitats ambivalents}

Hi ha parèmies que mostren la dona amb qualitats que poden considerar-se ambivalents. Fan referència a la seva tossuderia, que també podem interpretar com a perseverança, amb la qual cosa aquesta característica es pot veure com a negativa o com a positiva depenent de les circumstàncies: El que vol la dona, ho vol Déu (D I687); Sempre les dones surten amb la seva (D I845). Altres parèmies fan referència al fet que la dona és qui mana, una característica que, de fet, tampoc és positiva o negativa en ella mateixa: Benvolent o malvolent, de la dona sies parent (D I573); Vingues d'a on vingues, de part de la dona sies (D I885).

\subsection{Com ha de ser o com s'ha de comportar la dona}

La imatge de com ha de ser o com s'ha de comportar la dona es troba representada a través dels trets següents:

I. La dona ha de ser piadosa: Dona piadosa és sempre hermosa (D I643).

2. La dona ha de ser honesta: La dona més honesta és la més hermosa (D I736).

3. La dona ha de ser dòcil: A dona brava, corda llarga (D I548); A la dona i a la cabra, corda llarga (D I556); A la dona li convé més la vergonya que la valentia (D I559).

4. La dona ha de ser modesta, humil (no ha de ser vanitosa): A dona vanitosa no li allarguis la bossa (D I549).

5. La dona ha de ser virtuosa: A la dona has de jutjar en el beure $i$ caminar (D I555).

6. La dona ha de ser casta: A la dona casta, Déu li basta (D I553)

7. La dona ha de ser assenyada: Amb les dones de cap verd, qui més hi fa, més hi perd (D I568)

8. La dona ha de ser prudent: Dona prudenta, Déu la guia.

9. La dona ha de ser decorosa: Dona recatada és estimada (D I662); La dona honrada, ben recatada (D I729).

IO. La dona ha de ser humil: La dona humil val per mil (D I730).

II. La dona ha de ser llesta: La dona llesta i callada, de tots sempre és estimada (D I732).

I2. La dona ha de callar: La dona llesta i callada, de tots sempre és estimada (D I732); Per bé que la dona parlarà, li està millor el callar (D I8I7)

I3. La dona ha de ser discreta (saber guardar els secrets i no ser parladora): A la dona i a la garsa, el que sentis a la plaça (D I557); Dona xerradora conta el de casa i el de fora (D I666).

I4. La dona ha de ser treballadora (si passa molt de temps a la finestra o al balcó és que és poc treballadora): De dona finestrera, / camp vora de riera / i vinya vora camí ral, / no en traureu gaire cabal (D I578); Dona finestrera, malfeinera (D I609); Dona finestrera no farà llarga tela (D I6I2); Dona finestrera i vinya a prop de camí, solen tenir mala fi (D I6I3); Dona peresossa no val gran cosa (D I64I); Dona que molt bada, acaba tard la fusada (D I654); Dona que molt mira, poc fila (D I656). 
Aquest grup de parèmies sobre com ha de ser o com s'ha de comportar la dona també inclou les que fan referència a la relació que s'ha d'establir entre la dona i l'home.

I5. La dona s'ha de deixar influir per l'home: A la dona i a la vinya, l'home és qui la fa bonica (D I558).

I6. La dona ha de ser fidel al marit: La dona bona, un Déu i un home (D I700).

I7. La dona ha de ser submisa (s'ha de deixar maltractar): [A les dones] qui més bé els fa, / pitjor les ha (D I56I); Dona de Barberà i mula de Prades, abans no t'entri a casa, bat-li les cames (D I599).

I8. A la dona se l'ha de tenir subjecta: Les dones i els cavalls necessiten fre (D I78I).

I9. La dona ha de servir l'home (que pot explotar-la): Qui té dona, fa cabal (D I837); Qui té dona, té de tot (D I839); De la dona i del ruc, ne trec el que puc (D I579). Pel que fa a aquesta darrera parèmia, Farnés hi fa el comentari següent: «Serveix per expressar el migrat i envilit concepte que en general tenen les famílies, sobretot en les pagesies, del lloc que li correspon a la dona dintre de la casa; la dona ha de treballar de valent i aguantar els cops, com l'ase. La comparança, a fe, és ben poc cristiana.»

20. La dona s'ha d'estar a casa: La dona a la casa i l'home on faça falta (D I692); La dona que ix molt al carrer sol tenir la casa com un femer (D I75I); Les dones a casa $i$ els homes a la plaça (D I768).

2I. La dona ha de ser estalviadora: Si la dona no estalvia, cap jornal és prou (D I856).

22. La dona ha de ser endreçada: La dona endreçada és estimada (D I7I4).

23. La dona no ha de ser instruïda (ha d'ocupar-se de les coses que li són pròpies: les tasques domèstiques): Dona que parla en llatí, no la vull jo per a mi (D I658).

24. La dona ha de ser de la mateixa condició social que el marit: Dona de ton estament $i$ faràs bon casament (D I6OI), La dona amb qui et casaràs, fes que sigui del teu braç (D I693); Si a casar-te vas, busca dona del teu braç (D I848).

25. La dona jove no s'ha de casar amb un home vell: Ni dona jove amb home vell ni gat amb cascavell (D I805).

Finalment, un darrer grup de parèmies fan referència a quina ha de ser la imatge física de la dona:

26. La dona ha de ser fina de cara: A dona afaitada, gira-li la cara (D I546); $A$ dona barbuda, de lluny la saluda (D I547).

27. La dona ha d'anar ben pentinada: Dona escabellada, llorda segura (D I605).

28. La dona ha d'anar ben arreglada: La dona ben composta trau l'home d'una porta (D I698)

29. La dona ha de ser bonica: Dona bonica, no cal ser rica (D I588). La parèmia fa referència al fet que una dona bonica té el futur assegurat, ja que pot trobar fàcilment marit. La bellesa és, per tant, una qualitat molt valorada en la dona, tot i que tenir una dona bonica pot portar a l'home més d'un neguit, com s'ha vist reflectit en parèmies anteriors, i com reflecteixen també les parèmies següents que fan referència al fet que la dona no ha de ser presumida.

30. La dona ha de ser modesta (no ha de ser presumida per evitar ser sol-licitada): Dona de bell adorn és més perillosa que ballesta de torn (D I600); Dona presumida, mona vestida (D I645); Dona presumida, escurça-li la brida (D I646). 
Les parèmies estudiades presenten, d'una forma breu i efectiva, tota una sèrie de característiques atribuïdes a la dona sobre com és i sobre com ha de ser o s'ha de comportar. El conjunt de característiques mostra predominantment un model de dona, dòcil, virtuosa i discreta, en què la seva acció, un cop casada, es veu reduïda a l'àmbit familiar i subjecta a la voluntat del marit.

\section{Conclusions}

Hem pogut observar que Sebastià Farnés no era un simple recollidor de material folklòric, sinó que la tasca que de manera més persistent va desenvolupar durant la seva vida obeïa a unes conviccions, a una idea de la vida, de la cultura i del país. Convençut que la llengua i la literatura populars expressen l'esperit, l'ànima del poble, la seva activitat com a folklorista i, en concret, com a paremiòleg forma part de la més general com a catalanista: editor de periòdics, teòric, literat i pedagog.

L'estudi, des d'una perspectiva de gènere, de les 343 parèmies incloses a l'entrada «dona» de la Paremiologia catalana comparada (Farnés I992-I999) ha permès observar, d'una banda, que la imatge de «com és» la dona es manifesta a través d'unes qualitats positives, unes altres de negatives i, finalment, unes darreres d'ambivalents. En aquesta valoració, les parèmies que representen qualitats negatives de la dona són les més abundants. D’altra banda, la imatge de «com ha de ser o com s'ha de comportar» la dona, reflecteix una gran diversitat d'aspectes que responen a les expectatives esperables en una societat rural de generacions anteriors a la nostra i que es podrien resumir en una visió de la dona dòcil, virtuosa, discreta, eficient en l'àmbit familiar i subjecta a la voluntat del marit. 


\section{Referències bibliogràfiques}

AmAdes, Joan (I936): Refranyer de les dones. Barcelona: Biblioteca de Tradicions Populars [reedició Tarragona: El Mèdol 2004].

CONCA, Maria (I990): Paremiologia. València: Universitat de València.

ConcA, Maria; Josep Guia (20I4): La fraseologia. Principis, mètode i aplicacions. Alzira: Editorial Bromera.

FARNÉS, Sebastià (I882): «Un refran popular». La Renaixensa núm. I2: 77-79.

— (I883): «Refrans catalans». La Renaixensa núm. I3: 395-399.

- (I884a): «Refrans catalans». La Renaixensa núm. I4: I2I-I25.

- (I884b): «Refrans catalans. Qui no't conegui que’t compri». La Ilustració Catalana 5, núm. Io6: 75-77.

- (I9I3): Assaig de paremiologia catalana comparada. Volum I (Abarcar-Amich). Barcelona: Ilustració Catalana.

— (I9I8): «Folklore. Parèmies-endevinetes. Les tres gallines». Catalana: revista setmanal I, núm. 9: 2I8-220.

- (I928): «Demofilologia. Literatura oral. Sant Joan, bon sant». Arxiu de Tradicions Populars núm. I: II-I2 [ed. facsímil: Palma: Olañeta I992].

- [1929-I933a] (s. d.): «Demofilologia. Literatura oral. Dues cultures». Arxiu de Tradicions Populars núm. 4: I93-I99 [ed. facsímil: Palma: Olañeta I992].

— [I929-I933b] (s. d.): «Demofilologia. Literatura oral. Una endevineta proverbial». Arxiu de Tradicions Populars núm. 5: 264-266 [ed. facsímil: Palma: Olañeta I992].

— [i933] (s. d.): «Demofilologia. Literatura oral. Motius del rei En Pere d'Aragó». Arxiu de Tradicions Populars núm. 6: 336-338 [ed. facsímil: Palma: Olañeta I992].

- (I935): «Demofilologia. Literatura oral. Veïns perillosos». Arxiu de Tradicions Populars núm. 7: 20-23 [ed. facsímil: Palma: Olañeta I992].

- (I992-I999): Paremiologia catalana comparada. Edició a cura de Jaume VIDAL ALCOver, Magí Sunyer i Josep Lluís SAVAll. Amb la col-laboració de Josep M. PUJOL. Barcelona: Columna edicions, 8 vols.

FERnÁndez Poncela, Anna M. (2002): Estereotipos y roles de género en el refranero popular: charlatanas, mentirosas, malvadas y peligrosas. Proveedores, maltratadores, machos y cornudos. Rubí: Anthropos.

- (2004): Sexe i refranyer. Barcelona: CIM.

OrIOL, Carme (20I5): «Sebastià Farnés i la paremiologia catalana». Anuari de Filologia. Estudis de Lingüística núm. 5: I09-I26. 